\title{
Article \\ Environmentally Friendly Route for Fabricating Conductive Agent for Lithium-Ion Batteries: Carbon Nanoparticles Derived from Polyethylene
}

\author{
Jihye Mok ${ }^{1}$, Dalsu Choi ${ }^{1, *}$ and Suk Ho Bhang ${ }^{2, *}$ \\ 1 Department of Chemical Engineering, Myongii University, Yong-In 17058, Korea; wlgpqhtjr@mju.ac.kr \\ 2 School of Chemical Engineering, Sungkyunkwan University, Suwon 16419, Korea \\ * Correspondence: dalsuchoi@mju.ac.kr (D.C.); sukhobhang@skku.edu (S.H.B.)
}

Citation: Mok, J.; Choi, D.; Bhang, S.H. Environmentally Friendly Route for Fabricating Conductive Agent for Lithium-Ion Batteries: Carbon Nanoparticles Derived from Polyethylene. Catalysts 2021, 11, 424. https://doi.org/

10.3390/catal11040424

Academic Editor: Vincenzo Baglio

Received: 24 February 2021

Accepted: 23 March 2021

Published: 26 March 2021

Publisher's Note: MDPI stays neutral with regard to jurisdictional claims in published maps and institutional affiliations.

Copyright: (c) 2021 by the authors. Licensee MDPI, Basel, Switzerland. This article is an open access article distributed under the terms and conditions of the Creative Commons Attribution (CC BY) license (https:// creativecommons.org/licenses/by/ $4.0 /)$.

\begin{abstract}
Here, we introduce an environmentally friendly way of fabricating carbon nanoparticles which can be utilized as conductive agent for lithium-ion batteries (LIBs). Polyethylene (PE), which comprises the largest portion of plastic waste, was used as a source for carbon nanoparticle synthesis. Sulfonation allowed chemical structural transformation of innately non-carbonizable PE into a carbonizable conformation, and carbon nanoparticles could be successfully derived from sulfonated PE. Then, PE-derived carbon nanoparticles were used as conductive agents for LIBs, and assembled cells exhibited stable performance. Even though the performance is not as good as Super-P, utilization of PE as a source of conductive agent for LIBs might provide an economical advantage to upcycle PE.
\end{abstract}

Keywords: nanoparticles; environmentally friendly synthesis; conductive agent; Li-ion battery

\section{Introduction}

Lithium-ion batteries (LIBs), which have become an inseparable part of our daily life, consist of four major components: cathode, anode, electrolyte, and separator. Among those, the anode is where oxidation takes place and lithium ions and electrons are produced [1,2]. For efficient overall electrochemical reaction, generated electrons should be transported effectively throughout the anode. One of the most commonly used anode materials for fabricating LIBs is graphite [3]. However, even though graphite itself is considered as a conductive material, the microparticular shape of graphite for LIBs requires additional help for enhanced charge transport. Nanoparticular conductive agents are used to fill the microscale gaps between graphite particles and reduce contact resistance throughout the anode [1,3-5]. As a result, the introduction of conductive agents, which are commonly carbon nanoparticles, supports effective charge transport within anode. Therefore, conductive agents serve as a critical component for LIBs. In this article, we present an environmentally friendly route of producing conductive agents for LIBs which utilizes polyethylene (PE) as a source. $\mathrm{PE}$ is a commodity polymer which represents the largest production volume. Simultaneously, PE is the polymer with the largest volume in waste. On top of that, more critically, most of the PE waste is processed via landfill, which causes serious environmental problems [6,7]. In previous studies, sulfonation of PE was studied as a way to fabricate carbon fibers out of PE fibers [8-12]. Here, we demonstrate the fabrication of conductive agents for LIBs from PE, which might provide economically profitable cycle in reducing the volume of PE landfill. Through sulfonation at an elevated temperature, PE, which is an innately non-carbonizable material, could be successfully cross-linked and could develop carbon structure through heat treatment under an inert gas environment. The carbonized product from PE was then examined for its usage as a conductive agent for LIBs. LIBs assembled using PE-based carbon nanoparticles as conductive agents exhibited moderate capacitance when compared to the control samples based on Super-P, a reference commercial conductive agent. Still, LIBs based on PE carbon operate without any flaws. 
In summary, this study presents the possible application of $\mathrm{PE}$ as a source material for fabricating a conductive agent for LIBs. This might provide motivation for recollecting PE waste by ensuring economic profit, which will be due to a reduction in PE waste, which causes serious environmental problems.

\section{Results}

PE requires chemical structural changes to develop carbon structure upon high heat treatment because the molecule only contains single carbon bonds which easily dissociate during high heat treatment. Here, we utilized sulfonation to induce chemical structural transformation of linear PE chains into cyclic structures which can withstand high heat treatment and can evolve into carbon structures. For sulfonation, PE powders were immersed in sulfuric acid and sulfonated at the elevated temperature for $1 \mathrm{~h}$. Sulfonated PE powders were then filtered, washed with deionized water, and dried for further analysis. PE samples sulfonated at various temperature were first examined with dynamic scanning calorimetry (DSC) to track chemical structural changes of PE chains which are essential for successful carbonization.

Figure 1 presents DSC results of PE samples sulfonated at various temperatures and it can easily be deduced that PE chains started to be transformed into a new structure at $150{ }^{\circ} \mathrm{C}$. Endothermal melting peak of PE at $120^{\circ} \mathrm{C}$ started to deform when the sample was sulfonated at $150{ }^{\circ} \mathrm{C}$. As peak intensity showed an overall decrease, which is commonly seen behavior during the cross-linking process of polymers [13-15], we could expect that transformation of PE chains took place in a way to cross-link linear chains. However, we could not conclude complete cross-linking of PE chains because of the presence of endothermal residue. Still, the shape of the DSC peak remained unchanged after $150{ }^{\circ} \mathrm{C}$ even when sulfonation temperature was increased up to $170^{\circ} \mathrm{C}$, which at least ensured that possible transformation via sulfonation was completed at the $150{ }^{\circ} \mathrm{C}$.

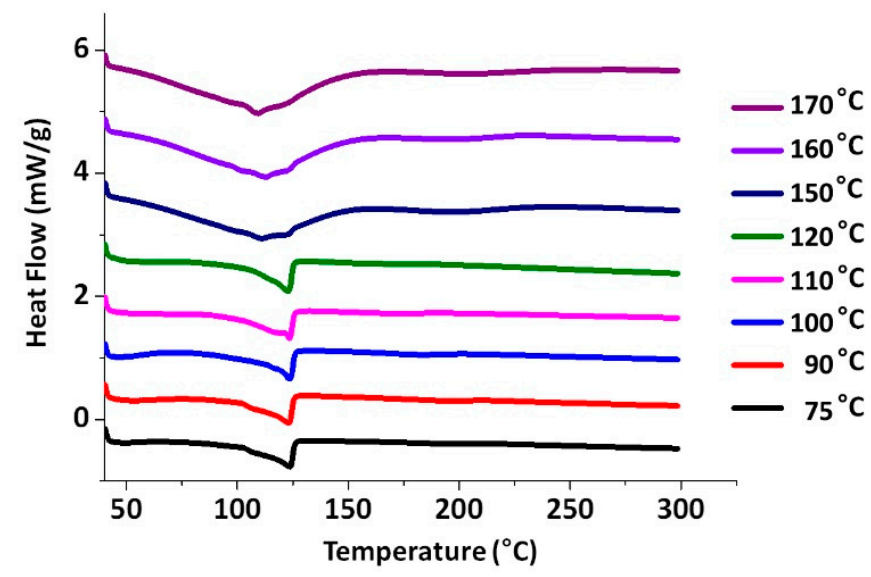

Figure 1. Dynamic scanning calorimetry (DSC) results for PE samples sulfonated at various temperatures.

The kinetic aspect of the reaction was also interrogated. PE samples were sulfonated at the fixed temperatures for elongated processing times. The DSC results of PE samples sulfonated at $150{ }^{\circ} \mathrm{C}$ for 1 and $4 \mathrm{~h}$, respectively, both exhibited matching results, which confirmed that $1 \mathrm{~h}$ was, kinetically, sufficient time for complete reaction (Figure S1).

Next, FT-IR was used to explore further chemical structural changes of PE upon sulfonation (Figure 2). Up to $120^{\circ} \mathrm{C}$ for sulfonation, the only noticeable change in spectra was the emergence of $\mathrm{S}-\mathrm{O}, \mathrm{S}=\mathrm{O}$, and $\mathrm{C}-\mathrm{O}$ bond peaks which appeared at 860, 1100, and $1200 \mathrm{~cm}^{-1}$, respectively [16]. Significant changes of spectra could be observed for the $150{ }^{\circ} \mathrm{C}$ sulfonated sample, which is concomitant to the result from DSC analysis. A doublet peak at 2840 and $2920 \mathrm{~cm}^{-1}$, representing the $\mathrm{C}-\mathrm{H}$ bond, completely disappeared. Such change indicates a significant degree of polymer chain cross-linking and therefore supports the DSC results, which suggested possible cross-linking initiation at $150{ }^{\circ} \mathrm{C}$ [17-20]. Further, 
ketone peak around $1700 \mathrm{~cm}^{-1}$ and $\mathrm{O}-\mathrm{H}$ single bond peak started to appear with the simultaneous disappearance of $\mathrm{C}-\mathrm{H}$ bonds. Changes in $\mathrm{O}-\mathrm{H}$ and $\mathrm{C}=\mathrm{O}$ bonds are related to attachment of oxygen functional group and sulfone functional group during the sulfonation process $[8,10,21,22]$.

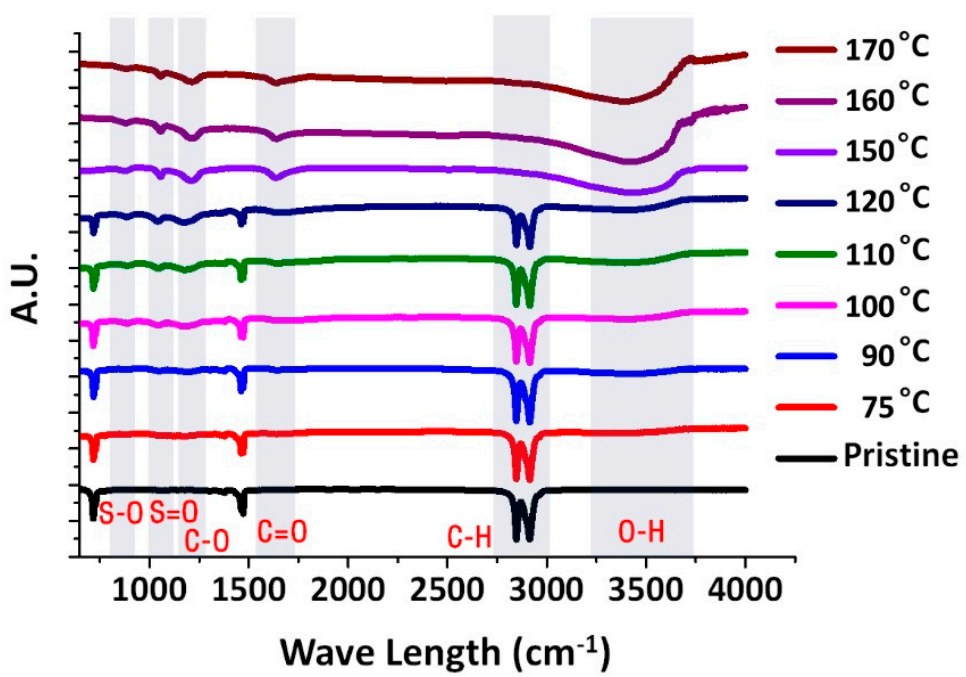

Figure 2. FT-IR results for polyethylene (PE) samples sulfonated at various temperatures.

Lastly, Raman spectroscopy was used to conclude chemical structural change of PE chains into a cyclic structure (Figure 3). Raman spectra of pristine PE sample exhibited fingerprint Raman peaks of common PE. Peaks at 1070 and $1130 \mathrm{~cm}^{-1}$ are related to $\mathrm{C}-\mathrm{H}$ stretching. The $\mathrm{CH}_{2}$ twist vibration of $\mathrm{PE}$ is represented by the $1300 \mathrm{~cm}^{-1}$ peak. Finally, a triplet spanning 1420 to $1500 \mathrm{~cm}^{-1}$ is related to $\mathrm{CH}_{2}$ bending vibration [23,24]. Next, Raman spectra of sulfonated PE sample was examined. It has been well studied in previous research interrogating structural development of the polyacrylonitrile (PAN) precursor that two characteristic Raman bands appear at 1400 and $1600 \mathrm{~cm}^{-1}$ when the cyclic structure has evolved [25-28]. A Raman band at $1400 \mathrm{~cm}^{-1}$ is from ring breathing vibration of cyclic structure and another at $1600 \mathrm{~cm}^{-1}$ is from stretching vibrational mode of carbon double bonds [28,29]. When the carbon precursor starts to develop polyaromatic cyclic structure, these two Raman bands start to emerge. Upon $150^{\circ} \mathrm{C}$ sulfonation, characteristic Raman peaks of pristine PE, which are mostly from $\mathrm{C}-\mathrm{H}$ bonding vibration modes, have disappeared, and Raman peaks at 1400 and $1600 \mathrm{~cm}^{-1}$ develop. Therefore, it can be argued that linear $\mathrm{PE}$ chains containing $\mathrm{C}-\mathrm{H}$ bonds are cross-linked into polyaromatic structures through high temperature sulfonation.

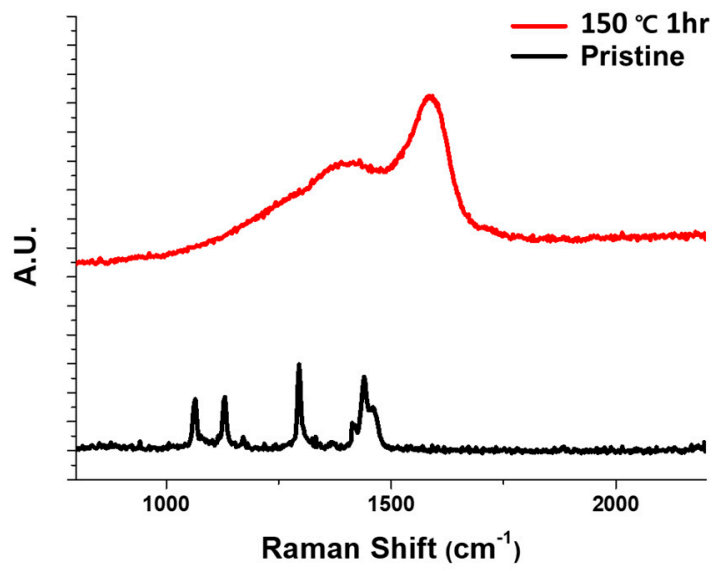

Figure 3. Raman spectra of PE samples before and after sulfonation. 
Moreover, both the shape and the ratio of peaks were comparable to those of peaks exerted by thermally oxidized PAN sample, which definitely contains polyaromatic cyclic structures. Hence, based on the Raman spectra of PE sample sulfonated at $150^{\circ} \mathrm{C}$, we could conclude that PE chains were successfully transformed into polyaromatic cyclic structures.

It is worth mentioning that the two Raman bands at 1400 and $1600 \mathrm{~cm}^{-1}$ are also characteristic fingerprints of the carbon structure, but it should be noted that the interpretation of these Raman bands has to be carefully made based on experimental circumstances. In this case, sulfonation of PE cannot simply derive carbon structure formation and it is logically sound to conclude that the Raman bands are related to the development of polyaromatic structure whose moieties are not as structured and as large as carbon materials $[25,28,29]$. In addition, the intensity ratio of these two bands is significantly higher in the case of carbon materials because the carbon structure consists of a well-constructed cyclic structure. The $\mathrm{D}$ to $\mathrm{G}$ intensity ratio spans 0.8 to 1.2 in the case of amorphous carbon while that of stabilized PAN whose chemical structure only includes polyaromatic moieties is well below 0.5 [28-30]. Therefore, the emergence of two Raman bands observed from Figure 3, with very low D to G ratio, should be interpreted as formation of polyaromatic moieties, not as formation of carbon structure.

After confirming successful chemical structural transformation of PE into cyclized structure through sulfonation, the sulfonated sample was then carbonized. PE sample sulfonated at $150{ }^{\circ} \mathrm{C}$ was carbonized at $1000^{\circ} \mathrm{C}$ with a ramping rate of $5^{\circ} \mathrm{C} / \mathrm{min}$. Carbonization was successful. The resultant carbon from sulfonated PE exhibited the characteristic Raman peaks of carbon materials (Figure 4a). The D to G peak ratio of carbonized PE sample was 1.03, and the value was comparable to that of Super-P, a reference carbonaceous conductive agent for commercial LIBs. As a result, it was confirmed that sulfonation made the successful development of carbon structure from PE possible. Successful carbonization of sulfonated PE again could be validated from competitive production yield (Figure $4 \mathrm{~b}$ ). Production yield of carbon materials from PE was determined based on thermogravimetric analysis (TGA) result. The value was $47.7 \%$, and it was similar to the production yield of PAN, a reference polymeric carbon precursor, reaching around 50\% [31,32].

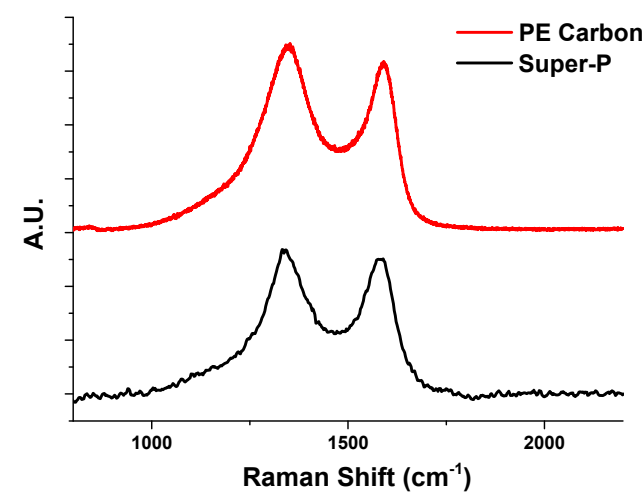

(a)

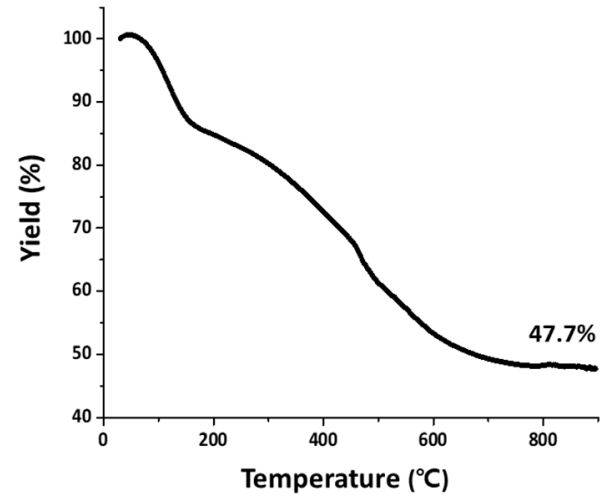

(b)

Figure 4. (a) Raman spectra of carbon derived from sulfonated PE (PE carbon) and SuperP. (b) Thermogravimetric analysis (TGA) results for sulfonated PE.

However, X-ray diffraction (XRD) results and powder conductivity results revealed major differences between PE-derived carbon powder and Super-P (Figure 5a). First, while lateral development of polyaromatic structure confirmed from Raman spectroscopy was similar, axial development of carbon structure was significantly varied. The Raman D band around $1400 \mathrm{~cm}^{-1}$ is strongly related to the clustering of aromatic moieties [27-29]. In the case of amorphous carbon structure, the development of carbon structure in the lateral direction induces development of the $\mathrm{D}$ band. However, it should be noted that $\mathrm{D}$ band development exhibits an inverse relationship to the degree of carbon ordering in the 
case of highly ordered graphitic carbon. Hence, the Raman spectra depicted in Figure 4 clearly show that PE-derived carbon and Super-P have comparable degree of carbon structural development in lateral direction. In XRD, completely different phenomenon was observed. D-spacing $\left(\mathrm{d}_{002}\right)$ and axial size of carbon crystallite $\left(\mathrm{L}_{\mathrm{c}}\right)$ were calculated based on characteristic (002) carbon peak around $25^{\circ}$. The Bragg angle of the (002) peak was used to calculate D-spacing, and $\mathrm{L}_{\mathrm{c}}$ was calculated based on the Debye-Scherrer equation using the full width at half maximum (FWHM) value of the peak $[29,33]$. While the D-spacing of Super-P was slightly smaller than that of PE-derived carbon, $\mathrm{L}_{c}$ was much bigger than that of PE carbon, indicating superior carbon structural development of Super-P in the axial direction. The difference in carbon structural development was reflected in conductivity. Before conductivity measurement, the PE carbon was ball-milled until the average size of the particles reached $0.315 \pm 0.228 \mu \mathrm{m}$ (Figure S3) to achieve a degree of contact resistance comparable to Super-P. Unfortunately, due to the limitations of top-down approach used in this study, the particle size distribution of resultant PE carbon was too broad to be accurately measured. Still, the overall size of particle was in sub-hundred-nanometer scale. According to the previous reports, conductive agents cannot be effectively mixed with active anode materials when the particle size is too large [34,35]. In this study, ball-milled PE carbon could be successfully mixed with active materials without phase separation, which ensures that the particle size is small enough.

(a)

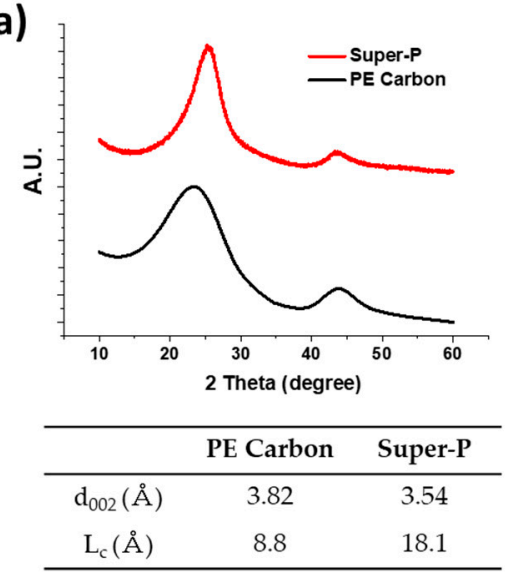

(b)

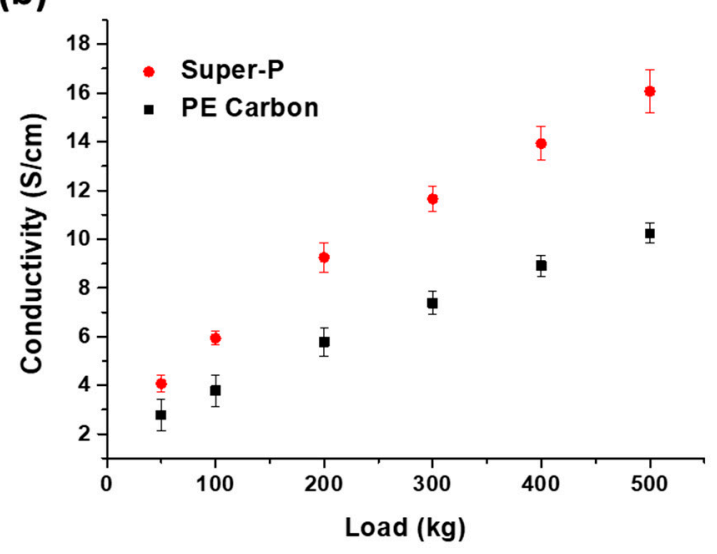

Figure 5. (a) XRD results and (b) electrical conductivity of carbon nanoparticle for PE and Super-P.

Electrical conductivity exhibited concomitant results following the trends observed in XRD (Figure 5b). Electrical conductivity of Super-P, which has shown a more ordered carbon structure in the axial direction, was significantly higher than for the carbon from the PE sulfonated at $150^{\circ} \mathrm{C}$ for $1 \mathrm{~h}$. PE carbons derived from other sulfonation conditions were also examined to obtain enhanced electrical performance of PE.

However, varied sulfonation time and temperature did not have any effect on the electrical conductivity of carbonized samples (Figure S4). Both elongated processing time and temperature did not provide any improvement in conductivity of the final carbonized products. Moreover, carbonization temperature was also elevated to $2000{ }^{\circ} \mathrm{C}$ to explore further changes, but the degree of ordering remained at the similar level, showing hard carbon characteristics (Figure S5) [36,37]. Even though its value is not as good as Super-P, the carbon derived from sulfonated PE still has sound electrical conductivity enough for it to be utilized as a conductive agent for fabricating LIB anodes. Finally, LIBs were fabricated using PE carbon as a conductive agent and compared to LIBs assembled based on Super-P. For anode fabrication, graphene oxide (GO) was used as active anode materials and polyvinylidene fluoride (PVDF) was used as binder material. Ball-milled PE carbon exhibited excellent mixing characteristic with GO and anode could be successfully 
fabricated. Fabricated anodes were assembled into coin cell with half-cell configuration consisting of lithium counter electrode and lithium hexafluorophosphate $\left(\mathrm{LiPF}_{6}\right)$ electrolyte.

Figure 6 depicts the electrochemical performance of cells which were fabricated using Super-P and PE-derived carbon, respectively. PE carbon served well as a conductive agent and a properly working cell could be fabricated. However, the capacitance of LIBs fabricated from PE carbon was $365.18 \mathrm{mAh} / \mathrm{g}$, whose value was significantly lower than LIBs made from Super-P. This is probably because PE carbon had lower electrical conductivity than Super-P. However, at the high current cycle of $1 \mathrm{C}$, capacitance of LIBs from PE carbon and Super-P were at the comparable range, whose values were 90.43 and $104.23 \mathrm{mAh} / \mathrm{g}$, respectively.

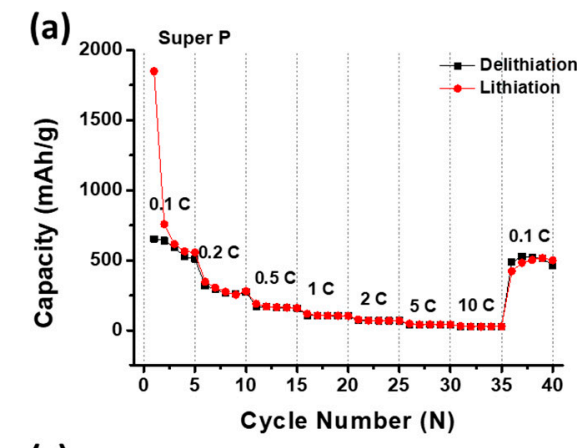

(c)

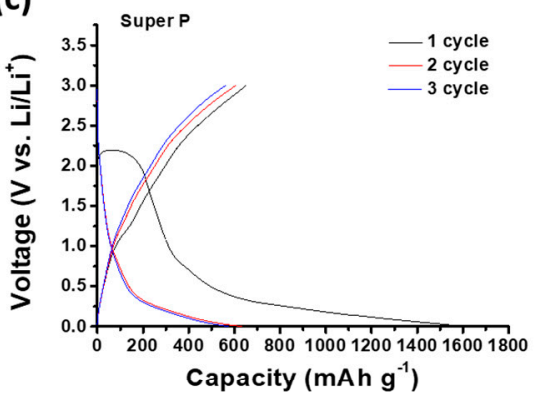

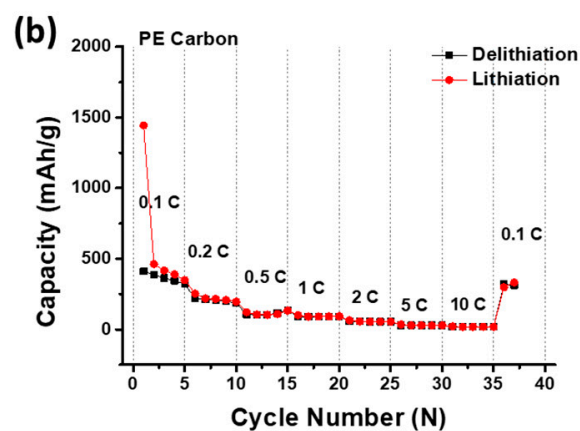

(d)

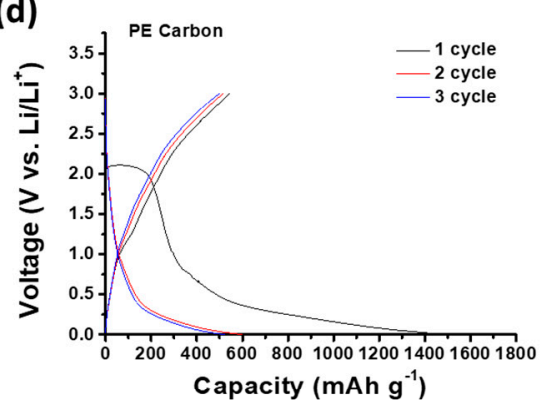

\begin{tabular}{|c|c|c|c|c|c|c|c|c|c|}
\hline & & $0.1 \mathrm{C}$ & $0.2 \mathrm{C}$ & $0.5 \mathrm{C}$ & $1 \mathrm{C}$ & $2 C$ & $5 \mathrm{C}$ & $10 \mathrm{C}$ & $0.1 \mathrm{C}$ \\
\hline \multirow{2}{*}{$\begin{array}{c}\text { GO + } \\
\text { Super-P }\end{array}$} & $\begin{array}{c}\text { Capacitance } \\
\text { (mAh/g) }\end{array}$ & 583.61 & 281.46 & 163.06 & 104.24 & 68.25 & 40.54 & 26.46 & 501.72 \\
\hline & $\begin{array}{c}\text { Retention rate } \\
\text { (\%) }\end{array}$ & 100 & 48.23 & 27.94 & 17.86 & 11.69 & 6.95 & 4.53 & 85.99 \\
\hline \multirow{2}{*}{$\begin{array}{c}\text { GO + } \\
\text { PE Carbon }\end{array}$} & $\begin{array}{c}\text { Capacitance } \\
\text { (mAh/g) }\end{array}$ & 365.18 & 205.33 & 112.25 & 90.43 & 54.92 & 28.44 & 17.56 & 315.59 \\
\hline & $\begin{array}{c}\text { Retention rate } \\
\text { (\%) }\end{array}$ & 100 & 56.23 & 30.74 & 24.76 & 15.04 & 7.79 & 4.81 & 86.42 \\
\hline
\end{tabular}

Figure 6. Cell performance of lithium-ion batteries (LIBs) assembled using Super-P and PE carbon as conductive agent. Capacity and the coulombic efficiency (CE) of LIBs from (a) Super-P and (b) PE carbon at 0.1-10 C-rate. Galvanostatic charge/discharge curves of LIBs from (c) Super-P and (d) PE carbon.

In summary, innately non-carbonizable PE could be transformed into carbonizable structure through sulfonation. Thorough analysis revealed chemical structural changes of PE through the sulfonation process, and successful carbonization could also be confirmed. More importantly, carbon nanoparticles fabricated from sulfonated PE could be utilized as a conductive agent for LIBs. Even though the performance was not as good as the reference commercial material Super-P, the LIBs fabricated from PE carbon nanoparticles exhibited sound performance. Such a demonstration envisions the possible upcycling pathway for PE waste, which is a serious worldwide environmental problem. Currently, recycling of PE does not provide solid economical profit. However, the possibility of transforming PE 
into a battery component, which ensures economic benefit, might promote collection of PE waste and, in turn, reduce the amount of PE waste.

\section{Materials and Methods}

\subsection{Experimental Details}

Sulfonation of PE was conducted by mixing linear low-density polyethylene (LLDPE) powder from Lotte Chemical (UL814) with sulfuric acid (98\%, Daejung Chemical, Korea). PE powder $(15 \mathrm{~g})$ was dispersed in $250 \mathrm{~mL}$ of sulfuric acid in a beaker and the mixture was heated up to the desired temperature using an oil bath. After sulfuric acid treatment, the entire mixture, including solid product and sulfuric acid, was poured into a water bath filled with $2 \mathrm{~L}$ of water for neutralization. After thorough mixing in the water bath, dispersion was filtered using glass fiber filter (GF/A, Whatman, UK). Filtered product was again washed with water until the $\mathrm{pH}$ of water was completely neutralized. Finally, sulfonated PE powder after washing was filtered using filter paper and dried in convection oven overnight.

Carbonization of sulfonated PE was conducted using box furnace. Chamber was purged with $\mathrm{N}_{2}$ for $1 \mathrm{~h}$ before carbonization. During carbonization, $\mathrm{N}_{2}$ gas was purged at $2000 \mathrm{sccm}$. Temperature was elevated up to target temperature with the ramping rate of $5{ }^{\circ} \mathrm{C} / \mathrm{min}$. Carbonized product was then ball-milled using planetary ball mill (Pulverisette 6, Fritsch, Germany) for $12 \mathrm{~h}$ with rotating speed of $400 \mathrm{rpm}$.

\subsection{Characterization}

Differential scanning calorimetry (DSC) was performed using a Q20 DSC (TA Instruments, New Castle, DE, USA) under $\mathrm{N}_{2}$ environment with a heating rate of $5{ }^{\circ} \mathrm{C} / \mathrm{min}$. Fourier transform infrared (FT-IR) spectroscopy measurement was conducted using Jasco FT/IR-6000 (Jasco, Japan). All the FT-IR spectra were obtained with the attenuated total reflectance (ATR) equipment. The instrument was equipped with a vacuum pump, and all the samples were measured under vacuum. Raman spectroscopy of samples were obtained using a Renishaw inVia Raman spectrometer (Renishaw, UK). Spectra were obtained with $514 \mathrm{~nm}$ laser at $0.15 \mathrm{~mW}$ of output power. Laser was focused through $20 \times$ optical lens and exposure time was $30 \mathrm{~s}$. Thermo gravimetric analysis (TGA) was performed using Setasys Evolution TGA (Setaram Instrument, France) under an $\mathrm{N}_{2}$ environment with a $5{ }^{\circ} \mathrm{C} / \mathrm{min}$ of heating rate. For X-ray diffraction (XRD) measurement, SmartLab XRD (Rigaku, Japan) with $\mathrm{Cu}-\mathrm{K} \alpha$ radiation $(\lambda=1.54 \AA)$ was used. $\mathrm{XRD}$ was operated at an acceleration voltage of $45 \mathrm{kV}$ and an emission current of $200 \mathrm{~mA}$. The $2 \theta$ value was scanned from 10 to $60^{\circ}$ at a scan speed of $10^{\circ} / \mathrm{min}$. Electrical conductivity of samples were measured using powder resistance measurement system (HPFM-M2, Hantech, South Korea). For anode fabrication, GO, conductive agent (PE carbon or Super-P), and polyvinylidene fluoride (PVDF) were mixed in the weight ratio of 80:10:10. PVDF was used as a binder material. The prepared mixture was coated on a copper foil using a doctor blade and then dried in a vacuum oven at $80{ }^{\circ} \mathrm{C}$ for $12 \mathrm{~h}$. CR 2032 coin-type cells were assembled in an argon-filled glove box. For cell assembly, Celgard 2400 was used as a separator and $1 \mathrm{M} \mathrm{LiPF}_{6}$ ethylene carbonate (EC) and dimethyl carbonate (DMC) mixture with volumetric ratio of 1:1 was used as electrolyte. Assembled cells were tested using a WBCS 3000 Automatic Battery Cycler system (Won A Tech, Daejeon, Korea).

\section{Conclusions}

In this article, we demonstrated the fabrication of carbon nanoparticles from polyethylene (PE), which takes up the largest volume of plastic waste. PE is innately non-carbonizable and cannot be transformed into useful carbonaceous materials. Using various physicochemical analysis methods, including DSC, FT-IR, Raman spectroscopy, TGA, and XRD, the chemical structural transformation of PE through sulfonation could be tracked, and it could be concluded that PE could be transformed into carbonizable chemical structure through sulfonation. As a result, sulfonation made carbonization of PE possible, and car- 
bon nanoparticles were synthesized from PE. Resultant carbon nanoparticles were tested as conductive agents for lithium-ion batteries (LIBs). Intriguingly, LIBs from PE-derived carbon properly operated and exhibited sound performance, which envisions possible upcycling pathway of PE as a LIB component.

Supplementary Materials: The following are available online at https:/ /www.mdpi.com/article /10.3390/catal11040424/s1. Figure S1: DSC measurements of PE sample with varied sulfonation time. Figure S2: FT-IR results for PE samples with varied sulfonation time. Figure S3: Representative scanning electron microscopy (SEM) image of ball-milled PE carbon. Figure S4: Powder electrical conductivity measurement of PE samples sulfonated for varied temperatures and times. Figure S5: XRD analysis results for sulfonated PE samples carbonized at various temperatures.

Author Contributions: Conceptualization, D.C.; methodology, D.C.; validation, J.M., D.C. and S.H.B.; formal analysis, J.M.; investigation, J.M.; resources, J.M.; data curation, J.M.; writing—original draft preparation, D.C.; writing-review and editing, D.C. and S.H.B.; visualization, D.C.; supervision, D.C. and S.H.B.; project administration, S.H.B.; funding acquisition, S.H.B. All authors have read and agreed to the published version of the manuscript.

Funding: This research was funded by 2019 Research Fund of Myongji University.

Conflicts of Interest: The authors declare no conflict of interest.

\section{References}

1. Li, H.; Wang, Z.; Chen, L.; Huang, X. Research on Advanced Materials for Li-ion Batteries. Adv. Mater. 2009, 21, 4593-4607. [CrossRef]

2. Odoom-Wubah, T.; Rubio, S.; Tirado, J.L.; Ortiz, G.F.; Akoi, B.J.; Huang, J.; Li, Q. Waste Pd/Fish-Collagen as anode for energy storage. Renew. Sustain. Energy Rev. 2020, 131, 109968. [CrossRef]

3. Hou, H.; Qiu, X.; Wei, W.; Zhang, Y.; Ji, X. Carbon Anode Materials for Advanced Sodium-Ion Batteries. Adv. Energy Mater. 2017, 7, 1602898. [CrossRef]

4. Azuma, H.; Imoto, H.; Yamada, S.N.I.; Sekai, K. Advanced carbon anode materials for lithium ion cells. J. Power Sour. 1999, 81-82, 1-7. [CrossRef]

5. Kaskhedikar, N.A.; Maier, J. Lithium Storage in Carbon Nanostructures. Adv. Mater. 2009, 21, 2664-2680. [CrossRef]

6. De Palmenaer, A. Polyethylene as a suitable precursor material for future carbon fibre production. In Proceedings of the Carbon Fibre Future Directions Conference 2017, Geelong, Australia, 1-3 March 2017.

7. Baker, F.S. Low Cost Carbon Fiber from Renewable Resources; U.S. Department of Energy: Washington, DC, USA, 2010.

8. Wortberg, G.; De Palmenaer, A.; Beckers, M.; Seide, G.; Gries, T. Polyethylene-Based Carbon Fibers by the Use of Sulphonation for Stabilization. Fibers 2015, 3, 373-379. [CrossRef]

9. Hunt, M.A.; Saito, T.; Brown, R.H.; Kumbhar, A.S.; Naskar, A.K. Patterned Functional Carbon Fibers from Polyethylene. Adv. Mater. 2012, 24, 2386-2389. [CrossRef]

10. Barton, B.E.; Patton, J.; Hukkanen, E.; Behr, M.; Lin, J.-C.; Beyer, S.; Zhang, Y.; Brehm, L.; Haskins, B.; Bell, B.; et al. The chemical transformation of hydrocarbons to carbon using $\mathrm{SO}_{3}$ sources. Carbon 2015, 94, 465-471. [CrossRef]

11. Choi, D.; Yoo, S.H.; Lee, S. Safer and more effective route for polyethylene-derived carbon fiber fabrication using electron beam irradiation. Carbon N.Y. 2019, 146, 9-16. [CrossRef]

12. Postema, A.R.; De Groot, H.; Pennings, A.J. Amorphous carbon fibres from linear low density polyethylene. J. Mater. Sci. 1990, 25, 4216-4222. [CrossRef]

13. Baum, B. The mechanism of polyethylene oxidation. J. Appl. Polym. Sci. 1959, 2, 281-288. [CrossRef]

14. Gugumus, F. Re-examination of the thermal oxidation reactions of polymers 2. Thermal oxidation of polyethylene. Polym. Degrad. Stab. 2002, 76, 329-340. [CrossRef]

15. Basfar, A.A.; Idriss Ali, K.M. Natural weathering test for films of various formulations of low density polyethylene (LDPE) and linear low density polyethylene (LLDPE). Polym. Degrad. Stab. 2006, 91, 437-443. [CrossRef]

16. Saxena, N.; Pal, N.; Ojha, K.; Dey, S.; Mandal, A. Synthesis, characterization, physical and thermodynamic properties of a novel anionic surfactant derived from: Sapindus laurifolius. RSC Adv. 2018, 8, 24485-24499. [CrossRef]

17. Song, Q.; Cao, S.; Pritchard, R.H.; Ghalei, B.; Al-Muhtaseb, S.A.; Terentjev, E.M.; Cheetham, A.K.; Sivaniah, E. Controlled thermal oxidative crosslinking of polymers of intrinsic microporosity towards tunable molecular sieve membranes. Nat. Commun. 2014, 5, 4813. [CrossRef] [PubMed]

18. Wind, J.D.; Staudt-Bickel, C.; Paul, D.R.; Koros, W.J. Solid-State Covalent Cross-Linking of Polyimide Membranes for Carbon Dioxide Plasticization Reduction. Macromolecules 2003, 36, 1882-1888. [CrossRef]

19. Tretinnikov, O.N.; Ogata, S.; Ikada, Y. Surface crosslinking of polyethylene by electron beam irradiation in air. Polymer 1998, 39, 6115-6120. [CrossRef] 
20. Suyama, S.; Ishigaki, H.; Watanabe, Y.; Nakamura, T. Crosslinking of Polyethylene by Dicumyl Peroxide in the Presence of 2,4-Diphenyl-4-methyl-1-pentene. Polym. J. 1995, 27, 371-375. [CrossRef]

21. Kazimi, M.R.; Shah, T.; Shima Binti Jamari, S.; Ahmed, I.; Ku Mohammad Faizal, C. Sulfonation of low-density polyethylene and its impact on polymer properties. Polym. Eng. Sci. 2014, 54, 2522-2530. [CrossRef]

22. Karacan, I.; Benli, H. Use of sulfonation procedure for the development of thermally stabilized isotactic polypropylene fibers prior to carbonization. J. Appl. Polym. Sci. 2012, 123, 234-245. [CrossRef]

23. Kotula, A.P.; Meyer, M.W.; De Vito, F.; Plog, J.; Hight Walker, A.R.; Migler, K.B. The rheo-Raman microscope: Simultaneous chemical, conformational, mechanical, and microstructural measures of soft materials. Rev. Sci. Instrum. 2016, 87, 105105. [CrossRef] [PubMed]

24. Visentin, M.; Stea, S.; De Clerico, M.; Reggiani, M.; Fagnano, C.; Squarzoni, S.; Toni, A. Determination of crystallinity and crystal structure of hylamer ${ }^{\mathrm{TM}}$ polyethylene after in vivo wear. J. Biomater. Appl. 2006, 21, 131-145. [CrossRef] [PubMed]

25. Tuinstra, F.; Koenig, J.L. Raman Spectrum of Graphite. J. Chem. Phys. 1970, 53, 1126-1130. [CrossRef]

26. Tamor, M.A.; Vassell, W.C. Raman “'fingerprinting"' of amorphous carbon films. J. Appl. Phys. 1994, 76, 3823-3830. [CrossRef]

27. Ferrari, A.C.; Meyer, J.C.; Scardaci, V.; Casiraghi, C.; Lazzeri, M.; Mauri, F.; Piscanec, S.; Jiang, D.; Novoselov, K.S.; Roth, S.; et al. Raman Spectrum of Graphene and Graphene Layers. Phys. Rev. Lett. 2006, 97, 187401. [CrossRef]

28. Ferrari, A.C.; Robertson, J. Raman spectroscopy of amorphous, nanostructured, diamond-like carbon, and nanodiamond. Philos. Trans. R. Soc. London A Math. Phys. Eng. Sci. 2004, 362, 2477-2512. [CrossRef]

29. Ferrari, A.C.; Robertson, J. Interpretation of Raman spectra of disordered and amorphous carbon. Phys. Rev. B 2000, 61, 14095-14107. [CrossRef]

30. Ferrari, A.C.; Basko, D.M. Raman spectroscopy as a versatile tool for studying the properties of graphene. Nat. Nanotechnol. 2013, 8, 235-246. [CrossRef]

31. Joh, H.-I.; Lee, S.; Kim, T.-W.; Hwang, S.Y.; Hahn, J.R. Synthesis and properties of an atomically thin carbon nanosheet similar to graphene and its promising use as an organic thin film transistor. Carbon 2013, 55, 299-304. [CrossRef]

32. Jung, C.-H.; Kim, W.-J.; Jung, C.-H.; Hwang, I.-T.; Khim, D.; Kim, D.-Y.; Lee, J.-S.; Ku, B.-C.; Choi, J.-H. A simple PAN-based fabrication method for microstructured carbon electrodes for organic field-effect transistors. Carbon 2015, 87, 257-268. [CrossRef]

33. Jurkiewicz, K.; Pawlyta, M.; Burian, A. Structure of Carbon Materials Explored by Local Transmission Electron Microscopy and Global Powder Diffraction Probes. C J. Carbon Res. 2018, 4, 68. [CrossRef]

34. Ogumi, Z.; Wang, H. Carbon Anode Materials. In Lithium-Ion Batteries; Springer: New York, NY, USA, 2009 ; pp. 1-25.

35. Spahr, M.E. Carbon-Conductive Additives for Lithium-Ion Batteries. In Lithium-Ion Batteries; Springer: New York, NY, USA, 2009; pp. 1-38.

36. Komaba, S.; Murata, W.; Ishikawa, T.; Yabuuchi, N.; Ozeki, T.; Nakayama, T.; Ogata, A.; Gotoh, K.; Fujiwara, K. Electrochemical Na Insertion and Solid Electrolyte Interphase for Hard-Carbon Electrodes and Application to Na-Ion Batteries. Adv. Funct. Mater. 2011, 21, 3859-3867. [CrossRef]

37. Buiel, E.; Dahn, J.R. Li-insertion in hard carbon anode materials for Li-ion batteries. Electrochim. Acta 1999, 45, 121-130. [CrossRef] 